\title{
USO DE METODOLOGIAS ATIVAS NO CURSO DE GRADUAÇÃO EM ENFERMAGEM: RELATO DE EXPERIÊNCIA
}

\author{
Aline Maino Pergola-Marconato \\ Enfermeira. Professora Doutora do curso de graduação em Enfermagem do \\ Centro Universitário Hermínio Ometto. \\ aline pergola@yahoo.com.br
}

INTRODUÇÃO: No cenário atual de acelerada atualização dos conhecimentos é imprescindível a reformulação do processo de ensino-aprendizado, com incorporação de metodologias que proporcionem ao estudante oportunidades de reflexão e ativa aplicação dos conceitos essenciais, por meio de atitude protagonista, enquanto o professor é facilitador. Assim, a transformação do modelo de educação tradicional na graduação em Enfermagem tornou-se premente. OBJETIVO: Descrever a experiência do curso de graduação em Enfermagem do Centro Universitário Hermínio Ometto com a aplicação de metodologias ativas de ensino-aprendizagem. MÉTODO: Trata-se de relato de experiência sobre a utilização dos métodos de ensino-aprendizado ativos e a avaliação da aplicação destes por meio da pesquisa de satisfação institucional realizada pelos alunos da Enfermagem no segundo semestre de 2017 e primeiro de 2018. Tal pesquisa tem caráter anônimo. RESULTADOS: A instituição de ensino disponibiliza capacitações frequentes aos docentes. $O$ processo formativo é dividido: revisão, conteúdo novo e síntese, com emprego de métodos como simulação realística, aprendizagem baseada em problemas (PBL) e aprendizagem baseada em times (TBL). São realizadas aulas práticas em laboratório, estudos de caso, quizz, mapa conceitual, papel minuto, entre outras. Nos últimos dois semestres, os alunos demonstram, na pesquisa de satisfação, percepção aumentada das metodologias empregadas pelos docentes, principalmente PBL e TBL. Há relatos também sobre a importância da realização de atividades práticas em ambiente de simulação. Os estudantes têm demonstrado, nos estágios do último ano, maior habilidade e segurança na realização da assistência. CONSIDERAÇÕES FINAIS: Os professores da graduação em Enfermagem capacitam-se e aplicam diversas estratégias pedagógicas para proporcionar postura acadêmica e profissional crítica e reflexiva para o desenvolvimento de competências e habilidades para o futuro enfermeiro. 
Palavras-chave: Educação em enfermagem. Ensino. Tecnologia educacional. 